\title{
Office Occupants' Mood and Preference of Task Ambient Lighting in the Tropics
}

\author{
Lim Gene-Harn ${ }^{1, a}$ Nila Inangda Manyam Keumala ${ }^{1}$ and Norafida Ad. Ghafar ${ }^{1}$ \\ ${ }^{1}$ Faculty of Built Environment, Universiti Malaya, Kuala Lumpur
}

\begin{abstract}
Office lighting is vital for energy savings and occupant's visual comfort being. Energy efficient lighting has been studied extensively in the aspect of daylighting harvesting and task ambient lighting, predominantly in Temperate developed countries. However, the lack of evident on the effectiveness of low ambient task lighting in the Tropics has prompted this paper to investigate the practicality of such lighting design for the Tropics. This paper explores into the office occupant's mood and preferences of low ambient daylight and usage of task light for the office in the Tropics. It also discusses the recorded work plane illumination level upon the usage of such lighting system. It studies the impact of such lighting design on people's preference, work plane illumination for three office spaces with the different luminous environment. In regards to the source of ambient lighting, two offices harvest daylight, and another uses the conventional overhead lights in accordance with MS1525 recommendations. Three of the offices have 15 samples respectively and the workspace horizontal illuminance level is measured across a month. The results of before and after the provision of task light reveal that the acceptance for low ambient task lighting system and it is widely preferred. However, the task light is not necessary utilized as some people are adapted to do computer work under low ambient lighting ( $(50-1501$ lux $)$. It shows that people's preference for work plane illuminance varies greatly. Many agree that they are in control with their personal lighting environment when an appropriate glare-free task light is being used. The paper recommends that office luminous measurement shall take other lighting parameters such as the vertical illuminance and luminance ratio into consideration for future research.
\end{abstract}

\section{Introduction}

With all the increasing inhabitants and also commercialization of which pose increasing the need for building services and increasing time spent in building, office lighting design contributes substantially to the primary domains of energy efficiency and visual comfort. This paper aims to seek for efficient workplace lighting design with the Tropics which in turn fits this the latest aspiration of energy efficient green buildings and improved work productivity. With MS1525:2014 as a benchmark reference, this paper compares the post occupancy (POE) visual comfort preferences of the usage of an ergonomic task light for three office spaces with variations in the luminous environment. This is a continuation of a prior working pilot paper which faced limitation in the size of test subjects and measuring period [1]. However, due to technical limitations, the energy efficiency of the compared lighting systems is not explored. Section 2 looks into prior analysis testimonials and also forms the parameter framework for this lighting analysis. Section 3 describes the triangulation methodology for in-situ illuminance measurement and POE. The result and discussion are elaborated concurrently in Section 4. Section 5 concludes the findings and recommends further research.

\section{Literature Review}

\subsection{Office Lighting \& Visual Comfort}

Many review papers, which commonly fall into daylighting, have discussed the impact of workplace lighting towards human preference since late 20th century [2-7]. There exists an agreement that people have a preference over appropriate daylighting design as oppose to artificial lighting. Galasiu \& Veitch [5] summarizes 60 papers on daylighting covering from 1965 and 2004 in understanding the interaction between occupants and daylighting. Boyce [3] reviews attempts on linking daylight and productivity while Sullivan et al. [7] looks into the methodology for assessing productivity in lighting environment. Nonetheless, occupant's interaction with daylighting also depends on the lighting automation system that will ensure effective lighting energy savings [2].

\footnotetext{
a'Lim Gene-Harn: limgeneharn@gmail.com
} 


\subsection{Daylighting}

An effective daylighting system depends on how daylight is channeled and distributed throughout the depth of the room uniformly [8]. David Strong [6] presents that human health, happiness, and well-being are inextricably linked to daylighting across various building functions. Daylight also acts as a variation of luminance and colors that strengthen attractiveness, trigger emotions and affect our mood [9]. The luminous environment acts through a chain of mechanisms on human physiological and psychological factors, which further influences human performance and productivity [10]. Daylight has a significant level of blue spectrum light that stimulates the circadian system, which could affect people's alertness and mood $[11,12]$.

However, daylighting is widely associated with the provisions of the window as people desire for a connection to the outside $[5,13,14]$. Libby [14] surveyed 155 subjects in Tennessee and found windows are the most desirable amenity in an office over desk location or size. A study on 8000 students in 450 classrooms in California also reveals that students appreciate vegetation or object views in the far distance, however, sun penetration and lack of window control can deteriorate learning [13]. Galasiu \& Veitch [5] also studied that visual comfort is affected by the physical dimension and transparency of the window.

\subsection{Low Ambient and Task-Based Lighting}

However, daylighting is redundant when luminous ratio and illuminance ratio across the room vary greatly, which causes glare and dark spots [5]. Occupants most likely will alter the position of the blind due to the incoming sensation of heat and glare and it is never pulled up again, prompting artificial light to be switched on $[15,16]$. Nevertheless, various findings have shown that workers are able to tolerate low ambient light over desktop work (50-200 lux) [17-19]. Hence, the provision of task light enables worker's concentration by giving a variation of 1.5 to 3 times of the illuminance of the task plane to that of that background [2].

Occupants are also found to be in favor with the combined system with task lights as they have the sense of personalization and control over their localized lighting environment. Ultimately, Begemann et al. [20]

Table 1 Recommended Illuminance Level from Various Standards survey on 170 subjects in Netherlands show that individual lighting settings differed greatly from one person to another, which depends on the individual's sensitivity to light, quality of sleep, biological clock, and weather type. Loe [21] agrees that occupants prefer a space with 'visual interest'- or a degree of light variation that stimulating; and different occupants have a different preference of luminous environment depending on the type of task, in which the task light comes useful.

\subsection{Workplace Psychology}

There exists a complex mechanism in understanding how indoor environmental parameters affects social behavioral where various factors may mask over the effect of each other [22-24]. There are various facets of physical environments such as ambient conditions, workstation and workspace design that will affect the psychological processes which determine the outcomes of satisfaction on performance and health [22]. Rashid \& Zimring [24] explains additional intervention factors such as personal motives, aptitude, demographic factors and organizational work factors determine stress level.

A study of 10 office buildings in the Netherland also found that the view type and view quality and workplace density influence physical and psychological discomfort, but not the distance from windows [25]. Veitch et al. [23] elaborate that it is not the control over lighting, but those who work closely to their personal preference, show improved mood and higher satisfaction. The design of the workstation, particularly on the height of cubicle also affects productivity level via privacy and air circulation factors [26]. All these aforementioned factors on workplace satisfaction have to be accounted.

\subsection{MS1525 Daylight Parameter}

Prior to the formation of Green Building Index, MS1525 and other international standards have recommended the work plane illumination level for various functions as summarsized in Table 1. However, literatures discover that workplace people can tolerate lower illumination levels under daylight instead of artificial lighting. Escuyer \& Fontoynont [27] shows that people preferred light levels between 100-300 lux for computer work and 300-600 lux for non-computer work. Alrubaih et al. [2]

\begin{tabular}{|c|c|c|c|c|}
\hline Standards/ Codes & $\begin{array}{c}\text { Lighting } \\
\text { Level for Task }\end{array}$ & $\begin{array}{c}\text { Lighting Level } \\
\text { for Ambient }\end{array}$ & $\begin{array}{c}\text { Lighting Power } \\
\text { Density }\left(\mathrm{W} / \mathrm{m}^{2}\right)\end{array}$ & Source \\
\hline $\begin{array}{c}\text { Malaysia } \\
\text { Standards } \\
\text { MS1525 (2014) }\end{array}$ & $300-400$ & 200 & 14.00 & $\begin{array}{c}\text { Code of Practice on Energy Efficiency } \\
\text { and Use of Renewable Energy for Non } \\
\text { Residential [36] }\end{array}$ \\
\hline $\begin{array}{c}\text { ASHRAE/ IESNA } \\
\text { Standard 90.1- } \\
2007\end{array}$ & $300-400$ & $320-530$ & 11.90 & $\begin{array}{c}\text { American Society of Heating } \\
\text { Refrigeration, and Air Conditioner } \\
\text { Engineers [37] }\end{array}$ \\
\hline $\begin{array}{c}\text { Singapore } \\
\text { Standards } \\
\text { SS530:2006 }\end{array}$ & 500 & 300 & 15.00 & Standards Council of Singapore [38] \\
\hline
\end{tabular}




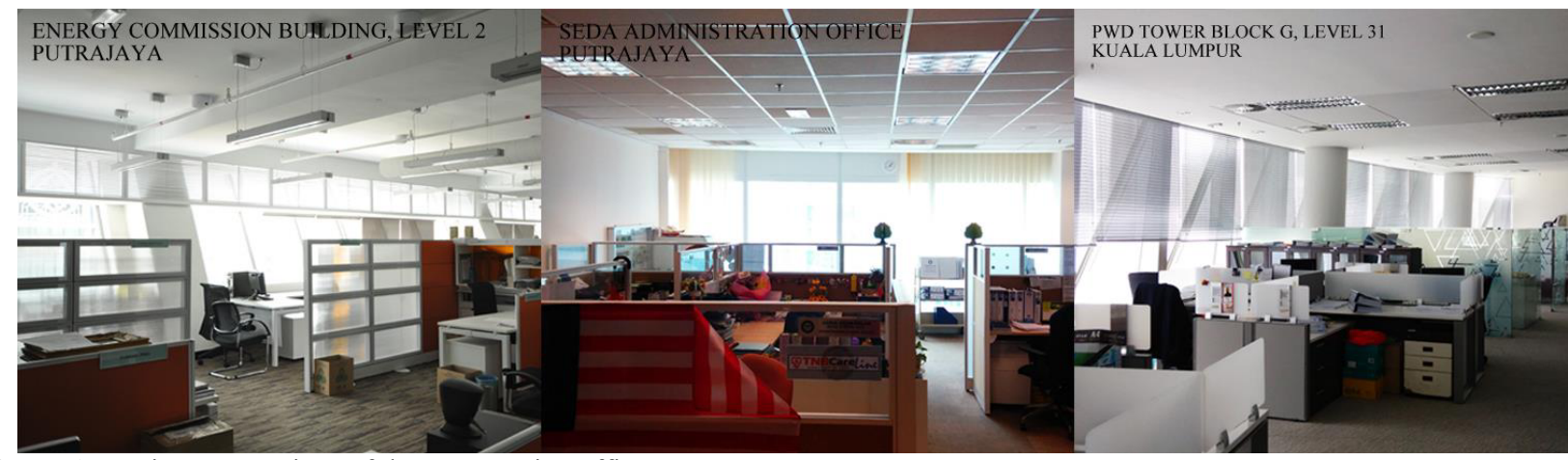

Figure 1 Interior perspectives of three respective offices

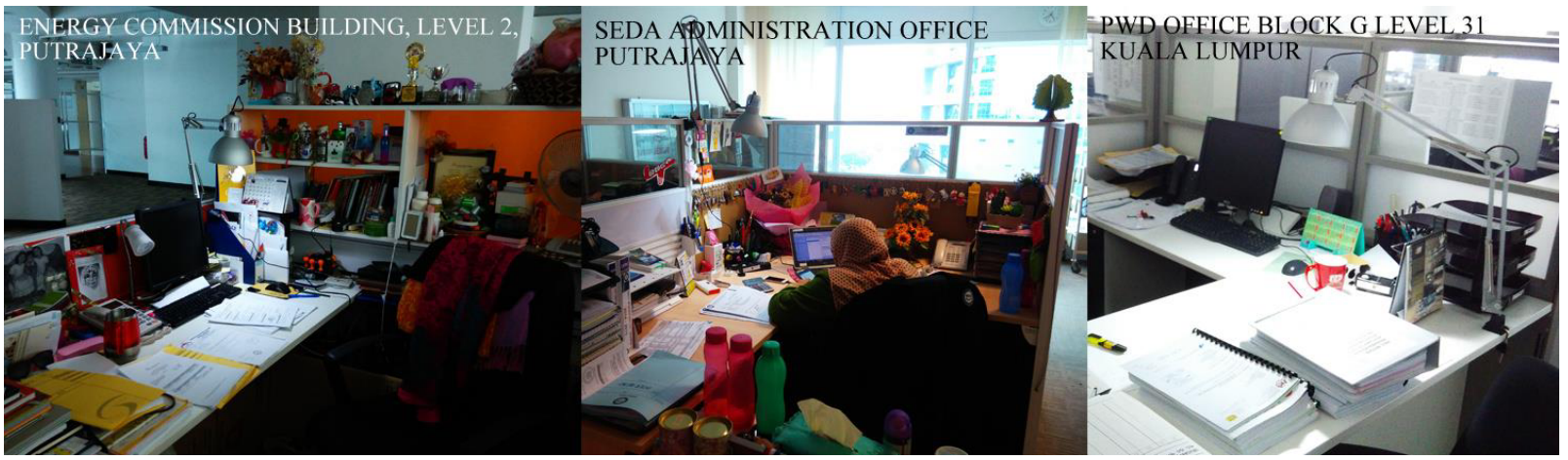

Figure 2 Illustration of IKEA's TERTIAL Task Light usage in respective offices

emphasize that the IESNA recommended illumination level is tailored to minimize lighting energy and are not designed to account for the intensity of sunlight. People are able to tolerate much lower illuminance levels of daylight than artificial light, in particular throughout diminishing daylight conditions towards the end of the evening, and the ones working on the computer tend to choose low illuminances (100-300lux) [28].

\section{Methodology}

As the research investigates the effectiveness of low ambient task light luminous environment, three different government agencies offices with varying ambient lighting conditions are selected. The interiors of Energy Commission building (ECB) in Putrajaya, SEDA ${ }^{\mathrm{a}}$ administration office in Putrajaya and PWD $^{\mathrm{b}}$ Tower Block G (PWD) in Kuala Lumpur are shown (Figure 1). All three office spaces have the same workplace density ( $10 \mathrm{~m}^{2} /$ occupant) and horizontal apertures opening to wall ratio. All window views are directed to large horizons of space and not subjected to nearby obstacles, exceptionally for PWD tower which oversees the Kuala Lumpur skyline. The ECB and PWD offices are equipped with light activation switch via lux sensors while SEDA office relies on conventional master switch control.

15 random samples from open cubicle workspaces are chosen based on the variety of orientation and distance from fenestration for each building. All samples are either from the Finance or Human Resources department, sharing the same work task typology which is predominantly computer-based work with minor paper reading. With no sensor loggers in place, it is assumed that all samples are at their desk most of the time. 15 units of TENMARS TM-203 illumination meters are placed on each work plane to record the illuminance level over a month at 5 minutes interval. 4 units of HOBO U12 loggers record the ambient temperature and relative humidity across the office space at 5 minutes interval.

The first half of the month records the current lighting level while the latter half records that of with the provision of an ergonomic task light (IKEA TERTIAL work lamp with $8 \mathrm{~W}$ fluorescent daylight bulb) to each individual (Figure 2). The recorded illuminance results are trimmed down working hour only $(8.30 \mathrm{am}-6.00 \mathrm{pm})$ of working weekdays. Online questionnaires in Malay language are given twice, before and after the provision of task light, which covers individual demographic, controllability of lighting, satisfaction of lighting on paper and computer work and a set of derived Pleasure, Arousal and Dominance (PAD) scale by A. Mehrabian [29], cited in [30]. However, the 6 points Likert scale are used instead of the semantic differential scale to the convenience of the subjects. 6 points agreement and satisfaction scale are used; 'very dissatisfied, dissatisfied, somewhat dissatisfied, somewhat satisfied, satisfied, very satisfied'. An alternative "no opinion" choice is included to enable the respondent to abstain from responding.

\footnotetext{
a Sustainable Energy Development Authority

b Public Works Department
} 


\section{Results \& Discussion}

\subsection{Illuminance Records}

The recorded illuminance readings are presented in two ways; an average illuminance trend of selected loggers over the working hours, and Useful Daylight Illuminance (UDI) $100 \%$ stacked bar concept proposed by Nabil \& Mardaljevic [31]. The average illuminance trend captures loggers that best represent all orientations and distance from window openings. Most workspaces located near fenestrations (less than 4 meters) have a great variation of illuminance readings and higher readings ( $>500$ lux $)$ than that of far from fenestration (beyond 4 meters) (Figure 3, 4 and 5). Significant measured results from ECB show distinctive low illuminance levels $(<2001 \mathrm{ux})$ at some workspaces, even when the workstations are near to the perimeter fenestration.

Due to the lack of task light usage sensor, the trend of task light usage is unknown from the measured results as there is no significant increase in illuminance level. This can be due to the logger is unable to capture the luminous coverage of the task light when in used. The measured results display a great diversity of illuminance level across all office spaces and most of them do not fall within the recommended range of 200-400lux by MS1525:2014. In order to quantify the occurrence of results within the MS1525 range, the alternative UDI interpretation reflects the percentage of occurrence for each logger's results (Figure 6, 7 and 8). The defined lux bracket range is altered from Nabil \& Mardaljevic [31]; $\mathrm{x}<200,200<\mathrm{x}<400$ and $\mathrm{x}>400$ (where $\mathrm{x}$ denotes lux level) in order to benchmark with the MS1525:2014 targets. It is found that the cumulative readings that fall within the MS1525:2014 range are 26.18\%, 30.09\% and $27.82 \%$ for ECB, SEDA, and PWD, respectively.

\subsection{Post Occupancy Evaluation - Visual Comfort}

There is total of 30 sets of questionnaires collected for each office, comprising before and after the provision of task light. Two set of the result are removed from SEDA office and PWC office each, as the respondents only occupied the work desk less than 2 months. The difference analysis of preference and mood are compared using the Mann-Whitney U test via IPSS software. The correlations of office parameters as well as compounded demographic are examined using Spearman's rho correlation

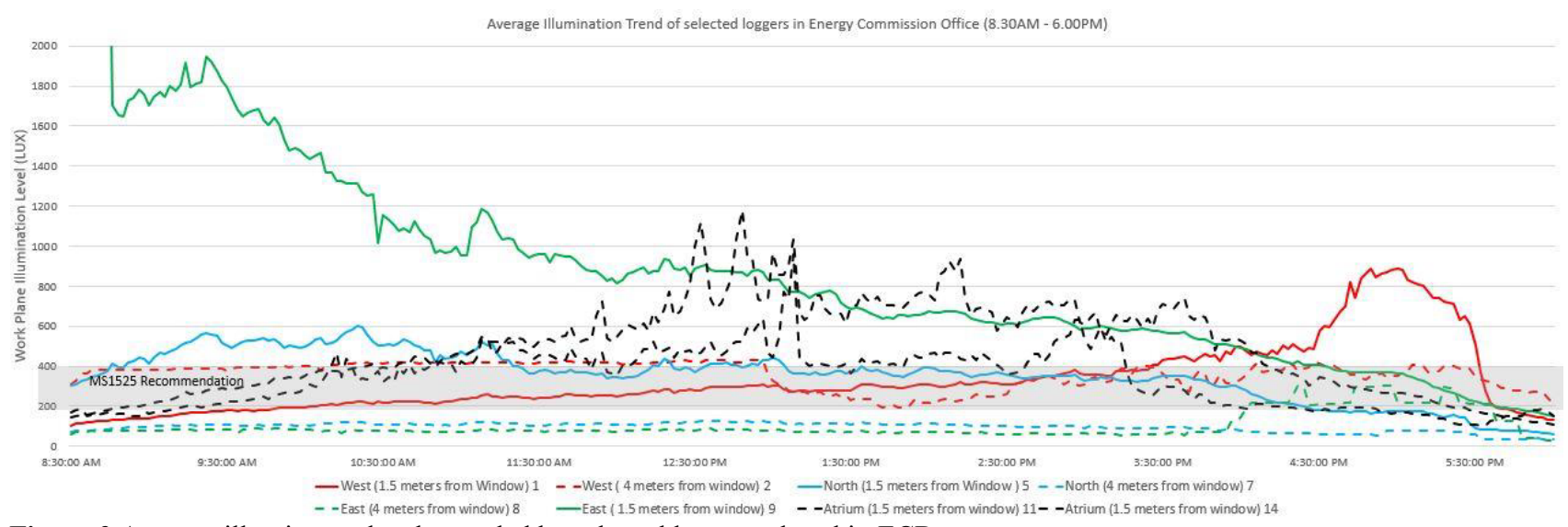

Figure 3 Average illuminance level recorded by selected loggers placed in ECB

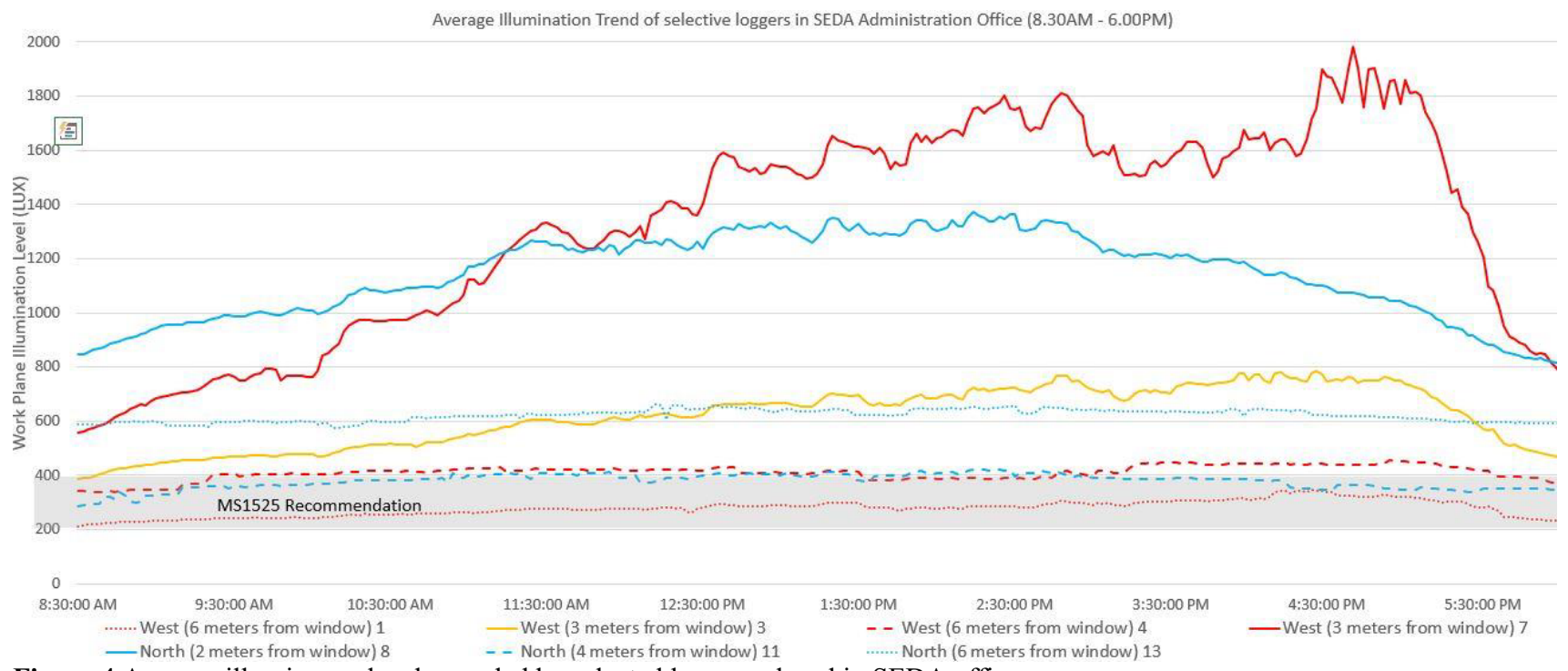

Figure 4 Average illuminance level recorded by selected loggers placed in SEDA office 


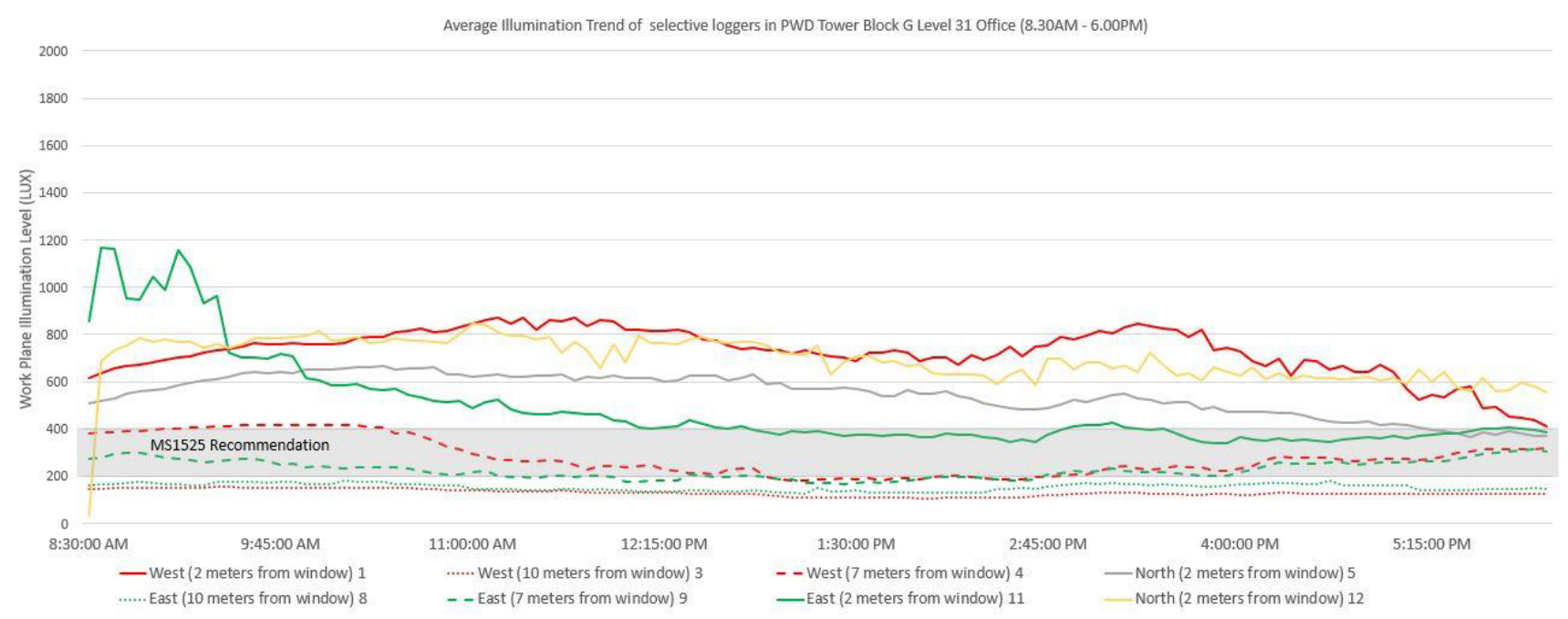

Figure 530 sets of recorded illuminance level on 15 samples in PWD Office

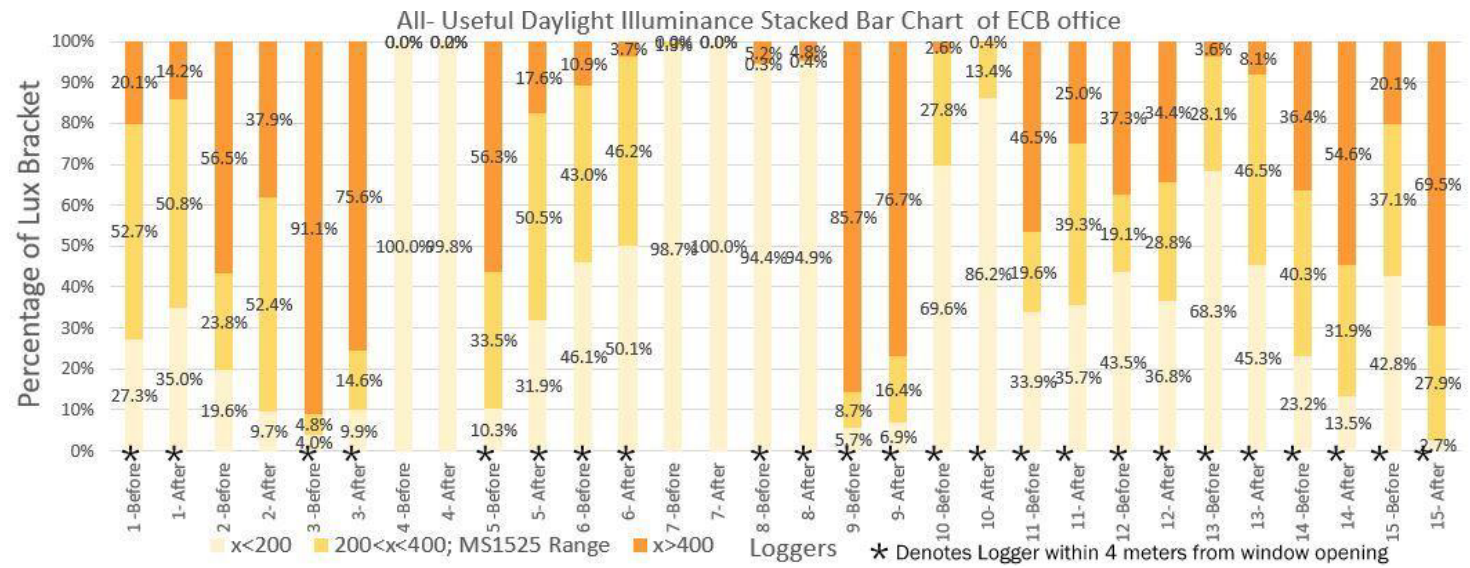

Figure 6 UDI of 30 sets of readings (before and after provision of task light) 15 lux loggers in ECB office

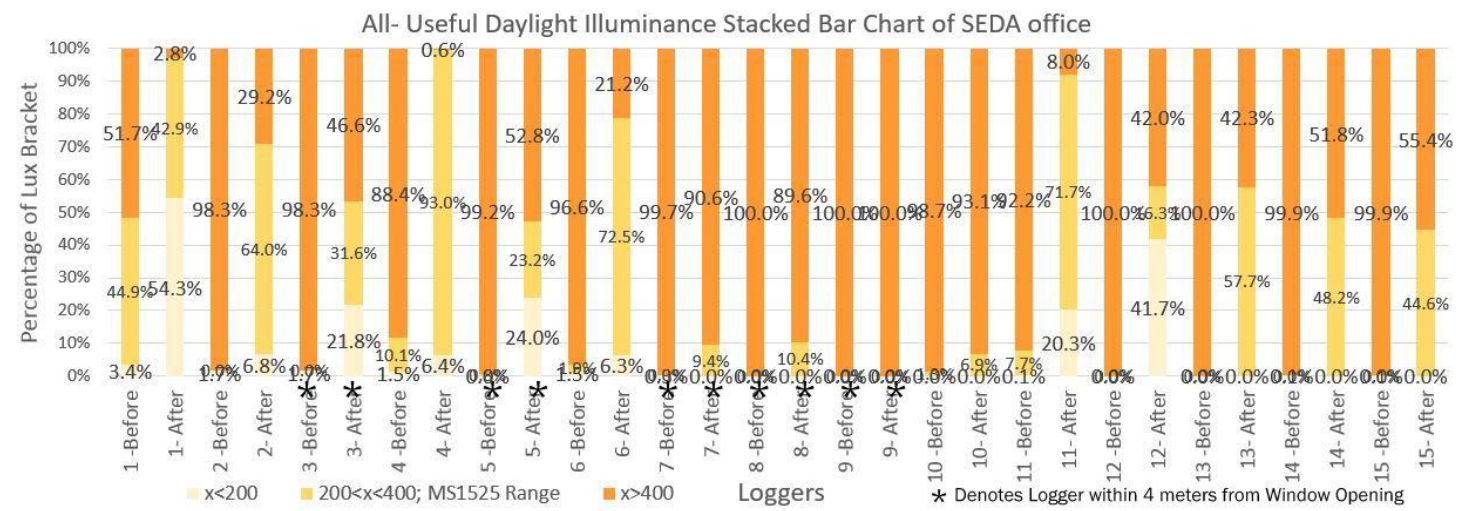

Figure 7 UDI of 30 sets of readings (before and after provision of task light) 15 lux loggers in SEDA office

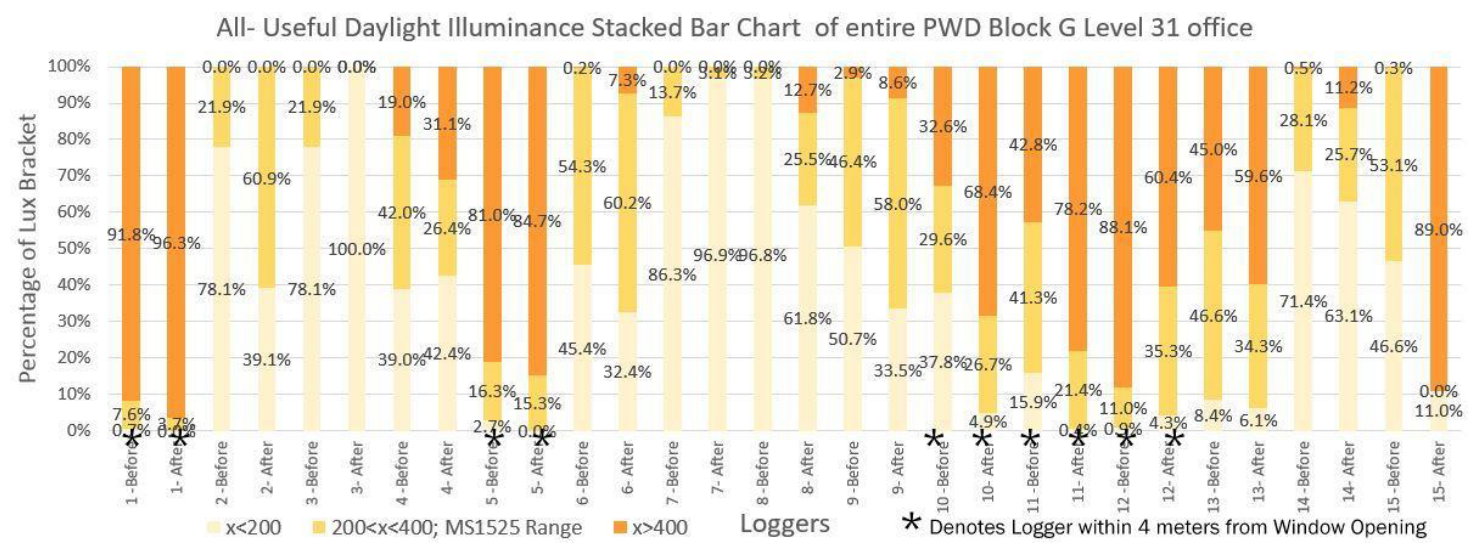

Figure 8 UDI of 30 sets of readings (before and after provision of task light) 15 lux loggers in PWD office 
Table 2 Differences in lighting satisfaction results for all 3 office spaces

\begin{tabular}{|c|c|c|c|c|c|}
\hline Satisfaction Level & $\begin{array}{l}\text { Lighting } \\
\text { Level }\end{array}$ & $\begin{array}{c}\text { Paper Work } \\
\text { Brightness }\end{array}$ & $\begin{array}{c}\text { Paper Work } \\
\text { Colour }\end{array}$ & $\begin{array}{c}\text { Computer Work } \\
\text { Brightness }\end{array}$ & $\begin{array}{c}\text { Computer } \\
\text { Work Colour } \\
\end{array}$ \\
\hline \multicolumn{6}{|c|}{ ENERGY COMMISSION BUILDING $(\mathrm{N}=30)$} \\
\hline MANN-WHitNEY U TEST & 39.000 & 64.000 & 73.000 & 92.000 & 101.500 \\
\hline $\mathrm{Z}$ & -3.354 & -2.122 & -1.882 & -.954 & -.510 \\
\hline ASYMP. Sig. (2-TAILED) & $.001 * *$ & $.034 *$ & .060 & .340 & .610 \\
\hline \multicolumn{6}{|c|}{ SEDA OFFICE $(\mathrm{N}=28)$} \\
\hline MANN-Whitney U TEST & 98.000 & 28.000 & 33.500 & 95.500 & 7.000 \\
\hline $\mathrm{Z}$ & .000 & -3.313 & -3.133 & -.137 & -4.636 \\
\hline ASYMP. SIG. (2-TAILED) & 1.000 & $.001 * *$ & $0.002 * *$ & .891 & $.000 * *$ \\
\hline \multicolumn{6}{|c|}{ PWD OfFICE $(\mathrm{N}=28)$} \\
\hline MANN-WHITNEY U TEST & 60.000 & 49.000 & 47.000 & 68.000 & 66.000 \\
\hline $\mathrm{Z}$ & -1.852 & -2.318 & -2.445 & -1.496 & -1.556 \\
\hline ASYMP. SIG. (2-TAILED) & .064 & $.020 *$ & $.014 *$ & .135 & .120 \\
\hline
\end{tabular}

$(*$ indicates $P<0.05 ; * *$ indicates $P<0.01)$

\subsubsection{Preference Comparison}

The Mann-Whitney $U$ test results for paperwork brightness are significant for all three offices (Table 2). There are no significant findings on computer work brightness and the provision of task light. The provision of task light helps in paperwork task but not computer work task in all three offices. P. Boyce et al. [32] supports this finding as task light helps in fine color discrimination paperwork while the computer screen is already a source of the luminaire. Despite, only ECB shows a significant difference in overall lighting satisfaction $(\mathrm{U}=39.00, \mathrm{P}<0.01)$. This can be attributed to the low work plane illumination level (<200lux). SEDA and PWD offices also register a significant difference in paperwork color rendering satisfaction. SEDA office finds a significant difference in computer work color rendering $(\mathrm{U}=7.00, \mathrm{P}<0.01)$. The variation of results shows that different offices have a different luminous environment which is not representative by a single horizontal point illuminance measurement of a workspace $[5,21]$.

\subsubsection{Mood Comparison}

Pleasure. 6 adjectives are used to represent the state of pleasure-displeasure mood. However, some adjectives are switched in order to suit the intended meaning due to the Malay language. Any significant difference found in mood is investigated for spearman's rho correlation with task light usage, window distance, the importance of view, controllability of local lighting and blinds, recorded range and variation of work plane illuminance level. The significance of difference of the various mood description related to pleasure to all 3 different office lighting scenes is shown (Table 3). For ECB, the lighting space is perceived as more 'Attractive' after the provision of task light however not significant $(\mathrm{P}>0.05)$. 'Cheerful' correlates with the frequency of task light usage $(\mathrm{r}=.648$, $\mathrm{P}<0.01)$. Results from SEDA office shows a significant correlation in describing the lighting as 'Cheerful', 'Beautiful' and 'Dynamic' with the controllability with work space light $(\mathrm{r}=.379, \mathrm{r}=.442, \mathrm{r}=.431$ respectively, $\mathrm{P}<0.05)$. There is a difference for 'Spacious' however not significant $(\mathrm{P}>0.05)$. There is a correlation of frequency of task light usage with 'Beautiful' $(\mathrm{r}=-.535, \mathrm{P}<0.01)$ and 'Enthusiastic' $(\mathrm{r}=-.454, \mathrm{P}<0.05)$. As for PWD office, there are significant correlations between 'Attractive' ( $\mathrm{r}=$ -.567, $\mathrm{P}<0.01)$ and 'Cheerful' $(\mathrm{r}=-.564, \mathrm{P}<0.01)$ to distance of nearest window. Controllability of workspace is significantly correlated with 'Attractive' $(\mathrm{r}=.512$, $\mathrm{P}<0.01)$ and 'Spacious' $(\mathrm{r}=.501, \mathrm{P}<0.01)$. Both recorded work plane illuminance range and diversity are significantly correlated with 'Attractive', 'Cheerful' and 'Spacious'. This means that the dynamics of luminous environment via blind control and work plane illuminance, together with perceived lighting controllability of workspace have improved the pleasure of lighting environment. Arousal.

Similarly, 6 adjectives are used to represent the state of arousal-non-arousal mood. The significance in difference of effects of lighting on mood is shown (Table 4). Results from ECB finds significant correlation of frequency of task light usage on 'Energetic', 'Excited', 'Wide Awake', 'Encouraged' and 'Happy'. Only 'Energetic' is found to be correlated significantly with window distance $(\mathrm{r}=-.421, \mathrm{P}<0.05)$, importance of view $(\mathrm{r}=-.361, \quad \mathrm{P}<0.05)$ and diversity of work plane illuminance $(r=-.421, \mathrm{P}<0.05)$. SEDA office lighting results shows all adjectives which have significant difference 'Excited', 'Determined', 'Wide Awake', 'Encouraged' and 'Happy' are significantly correlated with the frequency of task light usage $(\mathrm{P}<0.01)$ and the controllability of the lighting $(\mathrm{P}<0.05)$. No correlation relationships are found for the Arousal related mood with work plane illuminance level or diversity.

Results from PWD office finds a significant correlation between distance of window and 'Energetic' $(\mathrm{r}=-.416, \mathrm{P}<0.05)$, 'Excited' $(\mathrm{r}=-.506, \mathrm{P}<0.01)$ and 'Happy' ( $\mathrm{r}=-.636, \mathrm{P}<0.01)$. There is also significant correlation of frequency of task light usage for 'Energetic', 'Excited', 'Wide Awake', 'Encouraged' and 
Table 3 Difference in Pleasure related adjectives describing the lighting for all 3 office spaces

\begin{tabular}{|c|c|c|c|c|c|c|}
\hline The lighting of this space is & Attractive & Cheerful & Beautiful & Spacious & Dynamic & Enthusiastic \\
\hline \multicolumn{7}{|c|}{ Energy Commission Building $(\mathrm{N}=30)$} \\
\hline Mann-Whitney U Test & 71.500 & 33.500 & 87.000 & 78.500 & 97.500 & 81.000 \\
\hline $\mathrm{Z}$ & -1.889 & -3.487 & -1.132 & -1.489 & -.649 & -1.377 \\
\hline Asymp. Sig. (2-tailed) & .059 & $.000 * *$ & .257 & .137 & .516 & .168 \\
\hline \multicolumn{7}{|c|}{ SEDA Office $(\mathrm{N}=28)$} \\
\hline Mann-Whitney U Test & 66.500 & 58.500 & 52.500 & 59.000 & 56.000 & 51.000 \\
\hline $\mathrm{Z}$ & -1.647 & -1.990 & -2.305 & -1.862 & -2.205 & -2.529 \\
\hline Asymp. Sig. (2-tailed) & .100 & $.047 *$ & $.021 *$ & .063 & $.027^{*}$ & $.011 *$ \\
\hline \multicolumn{7}{|c|}{ PWD Office $(\mathrm{N}=28)$} \\
\hline Mann-Whitney U Test & 32.500 & 54.500 & 58.000 & 42.000 & 68.000 & 85.500 \\
\hline $\mathrm{Z}$ & -3.245 & -2.102 & -1.992 & -2.732 & -1.422 & -6.43 \\
\hline Asymp. Sig. (2-tailed) & $0.01 * *$ & $0.36^{*}$ & $0.046^{*}$ & $0.006^{* *}$ & .155 & .520 \\
\hline
\end{tabular}

(*indicates $P<0.05 ; * *$ indicates $P<0.01)$

Table 4 Difference in Arousal effects describing the effects of lighting for all 3 office spaces

\begin{tabular}{|c|c|c|c|c|c|c|}
\hline Light makes me feel... & Energetic & Excited & Determined & Wide Awake & Encouraged & Happy \\
\hline \multicolumn{7}{|c|}{ Energy Commission Building $(\mathrm{N}=30)$} \\
\hline Mann-Whitney U Test & 63.000 & 52.500 & 75.000 & 49.000 & 62.000 & 57.000 \\
\hline $\mathrm{Z}$ & -2.183 & -2.684 & -1.672 & -2.859 & -2.295 & -2.420 \\
\hline Asymp. Sig. (2-tailed) & $.029 *$ & $.007 * *$ & .095 & $.004 * *$ & $.022 *$ & $.016^{*}$ \\
\hline \multicolumn{7}{|c|}{ SEDA Office $(\mathrm{N}=28)$} \\
\hline Mann-Whitney U Test & 87.000 & 29.000 & 14.500 & 30.500 & 12.000 & 34.500 \\
\hline $\mathrm{Z}$ & -.539 & -3.383 & -4.030 & -3.184 & -4.306 & -3.105 \\
\hline Asymp. Sig. (2-tailed) & .590 & $.001 * *$ & $.000 * *$ & $.001 * *$ & $.000 * *$ & $.002 *$ \\
\hline \multicolumn{7}{|c|}{ PWD Office $(\mathrm{N}=28)$} \\
\hline Mann-Whitney U Test & 48.500 & 49.500 & 70.500 & 41.500 & 58.000 & 45.000 \\
\hline $\mathrm{Z}$ & -2.389 & -2.417 & -1.377 & -2.778 & -2.150 & -2.579 \\
\hline Asymp. Sig. (2-tailed) & $.017 *$ & $.016^{*}$ & .168 & $.005 * *$ & $.032 *$ & $.010^{*}$ \\
\hline
\end{tabular}

(*indicates $P<0.05 ; * *$ indicates $P<0.01)$

'Happy' $(\mathrm{P}<0.05)$. Blinds adjustment is significantly correlated with 'Excited' $(\mathrm{r}=-.442, \mathrm{P}<0.05)$ and 'Happy' $(\mathrm{r}=-.552, \mathrm{P}<0.05)$. Both work plane illuminance range and diversity are significantly correlated with 'Excited' and 'Happy' $(\mathrm{P}<0.01)$.

As shown from the variation of correlated luminous related parameters and mood adjectives across all 3 difference offices, the effectiveness of task light can be masked over by factors such as distance to the window, the importance of view or control of blinds. Sometimes the effectiveness of task light is supported by the perceived controllability of personal lighting environment and illuminance diversity, sometimes it contradicts with the frequency of the task light usage. There is no significant correlation found in work plane illuminance level and improved in the mood. This is possibly due to the illumination logger not registering the task light luminous coverage on work plane area.

\subsubsection{Demographic and Workspace Parameters Correlation}

Task light. Generally, there is a significant correlation between the usage of task light with overall light level satisfaction $(\mathrm{r}=.311, \mathrm{P}<0.01)$ and controllability of workspace lighting $(\mathrm{r}=.764, \quad \mathrm{P}<0.01)$. Significant correlation is also found with paperwork lighting $(\mathrm{r}=$ .494, $\mathrm{P}<0.01)$, paperwork color rendering $(\mathrm{r}=-.436$, $\mathrm{P}<0.01)$ and computer work color rendering $(\mathrm{r}=-.416$, $\mathrm{P}<0.01)$ but not with computer work lighting $(\mathrm{P}>0.05)$. The usage of task light has a significant correlation with all Pleasure and Arousal related description elaborated in section 4.2.1 and section 4.2.2. This is no surprise. However, there is no significant correlation of usage frequency with the distance of window from the work desk, work plane illuminance level, and diversity. The usage of task light is regardless of work desk position and illuminance condition. This result agrees that individual lighting preference varies [5] and the lighting satisfaction may be due to the perceived controllability of light rather than actual illuminance level [23].

Distance to Nearest Window and Lighting 
Preference. It is found that the distance of window to work desk is correlated with the satisfaction of lighting level $(\mathrm{r}=-.341, \mathrm{P}<0.01)$, and the importance of view $(\mathrm{r}=$ $.399, \mathrm{P}<0.01)$. This does not mask over the effectiveness of task light as a separate correlation analysis shows the usage of task light is regardless of distance to the window. There are significant correlations between lighting preference with distance to nearest window $(\mathrm{r}=$ $.618, \mathrm{P}<0.01)$, work plane illuminance range $(\mathrm{r}=.269$, $\mathrm{P}<0.05)$ and variation level of illuminance level $(\mathrm{r}=-.663$, $\mathrm{P}<0.01)$ and the preference remains unchanged with the provision of task light $(\mathrm{P}>0.05)$. The preference for daylight autonomy is influenced by the position of the work desk and its work plane illuminance dynamics across the day. There is no significant correlation of lighting preference with age or gender or condition of eyesight found. The majority of respondents prefer office environment with daylight as oppose to total reliance on electrical light (Figure 9).

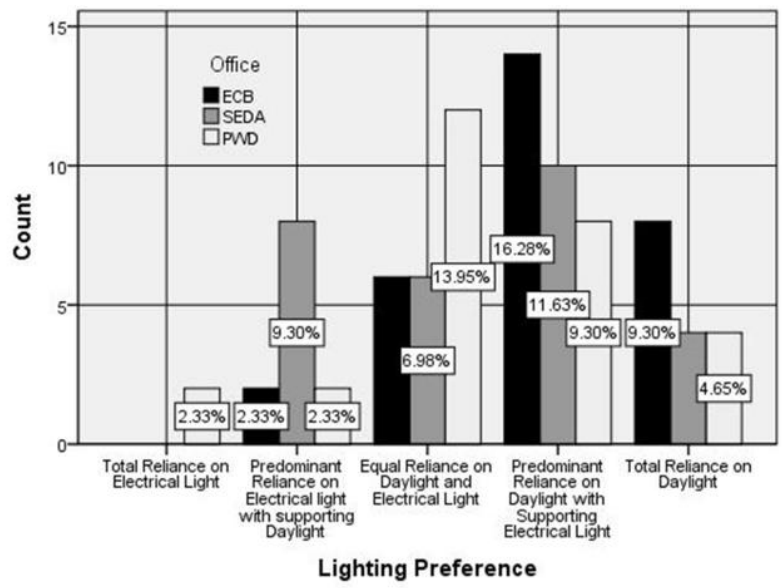

Figure 9 Lighting preference of 43 respondents across 3 offices

Age and Gender. The respondents' age has significant correlations with satisfaction of lighting level $(\mathrm{r}=.308$, $\mathrm{P}<0.01)$ and importance of window view $(\mathrm{r}=-.266$, $\mathrm{P}<0.05)$. This relates to the findings of Knez \& Enmarker [33] that older people evaluated room light as less bright than younger counterparts. However, gender has no significant correlation with overall lighting satisfaction level, opposing many researchers' findings that females being significant higher in positive aspects via Positive Affect and Sensation (PASS) test [34] and prefer lower light level in various color temperature [35].

Illuminance \& Satisfaction. There are no significant correlations found between work plane illuminance level and mood descriptions. However, the variation of illuminance range correlates significantly with the pleasure towards the lighting environment; 'Cheerful' ( $\mathrm{r}=$ -.355, $\mathrm{P}<0.01$ ), 'Spacious' ( $\mathrm{r}=-.281, \mathrm{P}<0.01)$, 'Dynamic' $(\mathrm{r}=-.596, \mathrm{P}<0.01)$, 'Enthusiastic' $(\mathrm{r}=-.297, \mathrm{P}<0.01)$; and the effects of the arousal, 'Energetic' $(r=-.298, \mathrm{P}<0.01)$, 'Excited' $(\mathrm{r}=-.320, \mathrm{P}<0.01)$, 'Determined' $(\mathrm{r}=-.285$,
$\mathrm{P}<0.01$ ), 'Encouraged' ( $\mathrm{r}=-.244, \mathrm{P}<0.05)$, 'Happy' $(\mathrm{r}=$ $.228, \mathrm{P}<0.05)$. This means that lighting satisfaction is independent of illuminance level but the constant variation in illuminance level throughout the day instead. Some subjects agree that they are more prone to be annoyed by sudden activated electrical light due to lux set point compared to working under low illuminance level.

Indoor Environmental Parameters. Spearman's Rho correlation analyzed the correlation of each office space indoor environmental quality parameters and lighting satisfaction level. There are no correlations of satisfaction of lighting level with the satisfaction levels of indoor temperature, air quality, noise level, cleanliness and office layout for ECB office. Results from SEDA office shows a significant correlation between satisfaction level of lighting and indoor air temperature $(\mathrm{r}=-.471, \mathrm{P}<0.05)$. Measured results from $\mathrm{HOBO}$ logger shows an average of $26^{\circ} \mathrm{C}$ across few respondents at a corner. PWD office shows a significant correlation between satisfaction on lighting and noise level $(\mathrm{r}=.405, \mathrm{P}<0.05)$.

\section{Conclusion \& Recommendation}

This paper investigates the effectiveness of task light with the different ambient illuminance level in 3 different government office spaces in the Tropics. Among the findings are:

-The lighting environment with the provision of task light elevates peoples' mood of pleasure and arousal.

- The provision of task light has increased the controllability of personal lighting environment, hence increased satisfaction on lighting level.

-The provision of task light helps in improving paper related task work, but not computer related task work.

-The frequency of task light usage is independent of illuminance level and distance from the nearby window.

-The lighting satisfaction is independent of illuminance level but the constant variation in illuminance level throughout the day instead, which supports why daylighting, even with low illuminance level is preferred. . $37 \%$ of respondents prefer office lighting environment with predominant reliance daylight with supporting electrical light.

-Individuals lighting preference varies and age are associated with, however not gender.

-Only $\sim 30 \%$ of work plane illumination records fall within the MS1525:2014 recommendation range for the 3 offices, despite improvement in mood and satisfaction towards the lighting environment.

The finding recommends further investigation on the task light be evaluated with other lighting parameters such as vertical illuminance or luminance mapping of the work desk environment. The ergonomics of task light such as glare free hood and flexibility to the workspace needs have to be further explored also. This research is supported by High Impact Research grant H-130001-00H000001 under Universiti Malaya. 


\section{References}

[1] L. Gene Harn, N. I. Manyam, and N. A. Ghafar, "Mood and Preference of Daylight and Task Light Design for the Office Space in the Tropics A Pilot Case Study," 2014.

[2] M. S. Alrubaih, M. F. M. Zain, M. a. Alghoul, N. L. N. Ibrahim, M. a. Shameri, and O. Elayeb, "Research and development on aspects of daylighting fundamentals," Renew. Sustain. Energy Rev., vol. 21, pp. 494-505, (2013)

[3] P. R. Boyce, "Reviews of Technical Reports on Daylight and Productivity," 2004.

[4] L. Edwards and P. Torcellini, "A Literature Review of the Effects of Natural Light on Building Occupants," 2002.

[5] A. D. Galasiu and J. a. Veitch, "Occupant preferences and satisfaction with the luminous environment and control systems in daylit offices: a literature review," Energy Build., vol. 38, pp. 728-742, (2006)

[6] D. Strong, "The distinctive benefits of glazing," 2012.

[7] J. Sullivan, M. Donn, and G. Baird, "Measuring Productivity in the Office Workplace," 2013.

[8] K. Johnsen, "Daylight in buildings, collaborative research in the International Energy Agency (IEA Task 21)," Renew. Energy, vol. 15, no. 1-4, pp. 142-150, (1998)

[9] P. R. Boyce, Chapter 3 : Lighting quality, 2nd ed. 2003.

[10] V. Gligor, "Luminous Environment and Productivity at Workplaces," Helsinki University of Technology, 2004.

[11] B. Plitnick, M. G. Figueiro, B. Wood, and M. . Rea, "The effects of red and blue light on alertness and mood at night," Light. Res. Technol., vol. 42, no. 4, pp. 449-458, Dec. (2010)

[12] A. R. Webb, "Considerations for lighting in the built environment : Non-visual effects of light," vol. 38, pp. 721-727, (2006)

[13] L. Heschong and F. Oaks, "Windows and Classrooms: A Study of Student Performance and the Indoor Environment," 2003.

[14] B. A. Libby, "Windows in the Workplace: A Comparison between Window Preferences and Preferences for Other Office Amenities among White Collar Workers," 2001.

[15] T. Inoue, T. Kawase, T. Ibamoto, S. Takakusa, and Y. Matsuo, "The development of an optimal control system for window shading devices based on investigations in office buildings," 2014.

[16] M. . Rea, B. Rutledge, and D. Maniccia, "Beyond daylight dogma," Daylighting '98 Conf. Proceeding an Int. Conf. Daylighting Technol. Energy Effic. Build., pp. 215-222, 1998.

[17] R. Kirsch and S. Volker, "Solid State Lighting in Offices: Impact on Lighting Quality and Room Appearance," Proc. CIE 2014 "Lighting Qual. Energy Effic., vol. 38, no. 1, pp. 88-95, (2014)

[18] R. Baron, M. S. Rea, and S. Daniels, "Effects of indoor lighting (illuminance and spectral distribution) on the performance of cognitive tasks and interpersonal behaviors: The potential mediating role of positive affect," Motiv. Emot., vol. 16, no. 1, pp. 1-33, (1992)

[19] C. Laurentin, V. Bermtto, and M. Fontoynont, "Light Source Type on Visual Appraisal," Light. Res. Technol., pp. 223-233, 2000.

[20] S. H. a. Begemann, G. J. van den Beld, and A. D. Tenner, "Daylight, artificial light and people in an office environment, overview of visual and biological responses," Int. J. Ind. Ergon., vol. 20, no. 3, pp. 231-239, (1997)

[21] D. Loe, "Energy efficiency in lighting -considerations and possibilities," Light. Res. Technol., vol. 41, no. 3, pp. 209-218, (2009)

[22] E. Sundstorm, "Workplace Environmental Psychology," in International Encyclopedia of the Social \& Behavioural Sciences, 2001, pp. 16593-16598.

[23] J. A. Veitch, M. G. M. Stokkermans, and G. R. Newsham, "Linking Lighting Appraisals to Work Behaviors," Environ. Behav., vol. 45, no. February 2013, pp. 198-214, (2011)

[24] M. Rashid and C. Zimring, "A Review of the Empirical Literature on the Relationships Between Indoor Environment and Stress in Health Care and Office Settings: Problems and Prospects of Sharing Evidence," Environ. Behav., vol. 40, pp. 151-190, (2008)

[25] M. B. C. Aries, J. a. Veitch, and G. R. Newsham, "Windows, view, and office characteristics predict physical and psychological discomfort," J. Environ. Psychol., vol. 30, no. 4, pp. 533-541, (2010)

[26] K. E. Charles and J. A. Veitch, "Environmental Satisfaction in Open-Plan Environment : 2 Effect of Workstation Size , Partition Height and Windows," 2002.

[27] S. Escuyer and M. Fontoynont, "Testing in situ of automatic ambient lighting plus manually controlled task lighting: office occupants reactions," Proc. Lux Eur. 2001 9th Eur. Light. Conf., 2001.

[28] N. Baker, "We are all outdoor animals," in Architecture City Environment, Proceedings of PLEA 2000, 2000, pp. 553-555.

[29] A. Mehrabian, "Pleasure-Arousal-Dominance: A General Framework for Describing and Measuring Individual Differences in Temperament," Curr. Psychol., vol. 14, no. 4, pp. 261-292, (1996)

[30] T. J. M. Van der Voordt, P. Vink, I. Bakker, and J. de Boon, "Pleasure, Arousal, Dominance : Mehrabian and Russell revisited," Curr. Psychol., vol. 10, no. 33(3), pp. 405-421, (2014)

[31] A. Nabil and J. Mardaljevic, "Useful daylight illuminances: A replacement for daylight factors," Energy Build., vol. 38, no. 7, pp. 905913, (2006)

[32] P. R. Boyce, C. Hunter, and O. Howlett, "The Benefits of Daylight through Windows," 2003.

[33] I. Knez and I. Enmarker, "Effects of Office 
Lighting on Mood and Cognitive Performance And A Gender Effect in Work-xRelated Judgment," Environ. Behav., vol. 30, no. 4, pp. 553-567, Jul. (1998)

[34] C. L. B. McCloughan, P. A. Aspinall, and R. S. Webb, "The impact of lighting on mood," Light. Res. Technol., vol. 31, no. 3, pp. 81-88, Sep. (1999)

[35] O. Shino, K. Akari, M. Tatsumoto, K. Okajima, and K. Hirata, "Preferable Lighting Conditions For Migraneurs to Relax in Room," in Proceedings of CIE 2014 "Lighting Quality and Energy Efficiency,” 2014, vol. 39, pp. 716-719.

[36] Departments of Standards Malaysia, MS1525 2014 Code of Practice on Energy Efficiency and Use of Renewable Energy for Non Residential Buildings (2nd Revision). 2014.

[37] ASHRAE, "ASHRAE 90.1," 2004.

[38] StandardsCouncilofSingapore, "SS530:2006 Code of Practice for Energy Efficiency Standard for Building Services and Equipments," 2006. 